Article

\title{
Digitalization: An Opportunity for Contributing to Sustainability From Knowledge Creation
}

\author{
Joaquín Ordieres-Meré 1,* (D), Tomás Prieto Remón ${ }^{2,3}$ (D) and Jesús Rubio ${ }^{4}$ \\ 1 PMQ Research Group, ETSII, Universidad Politécnica de Madrid José Gutiérrez Abascal 2, \\ 28006 Madrid, Spain \\ 2 ETSII, Universidad Politécnica de Madrid, José Gutiérrez Abascal 2, 28006 Madrid, Spain; prietoret@iata.org \\ 3 Customer and Business Services (CBS) division at IATA, 1215 Geneva, Switzerland \\ 4 Data \& Digital Content Department, MACS-BIS division at IATA, Montreal, QC H4Z 1M1, Canada; \\ rubioj@iata.org \\ * Correspondence: j.ordieres@upm.es; Tel.: +34-910677107
}

Received: 31 December 2019; Accepted: 11 February 2020; Published: 15 February 2020

check for updates

\begin{abstract}
This paper aims at exploring the perspective of sustainability when digital transformation is adopted by one organization, although it was not the first goal targeted. Two different cases are analyzed, covering manufacturing and service industries. In those cases different factors will be analyzed, mainly focused on the positive effects of knowledge creation facilitated by direct or indirect application of digitalization. Specific analysis of different cases were carried out to identify different initiatives and the impact on environmental performance. The positive effects of the institutional dimension were also assessed.
\end{abstract}

Keywords: digital transformation; industry 4.0; sustainability; air transport; organizational strategies; knowledge creation

JEL Classification: L52, L61, L87,L93

\section{Introduction}

There are different drivers that society is enforcing as relevant elements that professionals and decision makers need to care about. Some of those drivers can be identified as sustainability, digital transformation, innovation and entrepreneurship.

Those dimensions have become more and more relevant as specific threats like climate change can damage properties and infrastructures, which ends up hitting productivity, inducing mass migration, etc. A key aspect is the creation of value in a sustainable way, because it can directly contribute to the deceleration of climate change. Indeed it is aligned with the reduction of negative economic impacts; therefore, specific manufacturing activities can be developed to promote a circular economy [1]. To measure the level of achieved digitalization in a country, the European Commission developed the Digital Economy and Society Index (DESI), a composite measure that summarises indicators related to the digital performance and digital competitiveness of the EU member states [2]. It is compounded of a set of indicators related to the digital policy mix, where some authors [3] have compared with some other global approaches like the Global Entrepreneurship Index.

According to DESI, over the last years there has been a huge development in digital information, communication and systems. By implementing intelligent technologies on top of such systems, it is possible to have relevant influence on the quality of life on our planet.

Innovation trends in complex computerization and digitization of manufacturing processes and process activities like cloud manufacturing $(\mathrm{CMfg})$, which has emerged as a novel business paradigm 
for manufacturing industry, are a clear example. Such innovations enable dynamical scalability and virtualised management of resources as consumable services over the Internet, in such a way to understand manufacturing activity as a service [4]. These innovations as the CMfg are strongly related to the Industry 4.0 concept, that has been a driving force for the industry. The growing complexities of design and the need of efficient production practices have resulted in the evolution of manufacturing methods [5]. Cutting edge, distinct, and new manufacturing techniques and tools are consistently being developed to meet fluctuating market demands.

However, such a novel paradigm does not emerge in the manufacturing industry alone, but in many different economic sectors and, having a critical look at them, the air transportation sector has much to say because of the unforeseen effects of the globalization of trade, news and, in the end, because of the influence of social media [6,7].

Therefore, based on the previous discussion it becomes clear that digital transformation can help to foster innovation not only in products but also in processes and corporate strategy as well, with strong contribution from entrepreneur perspective [8]. Most of these relationships are grounded on specific key drivers such as Industry 4.0 and some other related concepts like IoT, IIoT, etc.

Despite the large research activity on the individual concepts like digitalization, digital transformation, Industry 4.0 applications, etc., not all the relevant dimensions between them have been deeply analyzed. In particular the authors are interested in understanding if digitalization can improve the institutional knowledge of organizations, helping to improve their environmental performance. Because of the limited research in the field, they do believe that is done through the consistent increase of the the institutional knowledge of how sustainable development is performed; in particular, when the main goal of undertaken actions does not address sustainability.

Then, the focus of the paper is to research whether digitalization can increase sustainable organizational performances, even if that was not the main goal of the activity, and the interest research question is, Can digitalization processes positively impact sustainability through actions that have an impact on organizational knowledge and, if so, what are the main mechanisms?

The paper's additional ambition is to propose a general framework where some accountability could be assigned to the different dimensions and to specific plans or strategies, in a life cycle view. Under such a perspective a more integrative perspective of digitalization effects can be foreseen. Regarding the Sustainable Development Goals (SDG) for industrial ecosystems, the presented approach addresses the SDG 9 "Industry, Innovation and Infrastructure" [9].

To cope with these goals, the structure of the paper will care about the current level of analysis regarding sustainability that the digitalization literature has discussed, taking care of the relevant concepts as well as their relationships in Section 2; at the end of the section a justification for the analysis being carried out is provided. In Section 3 the description of cases will be addressed, justifying the adopted approach and the level of analysis (micro for the manufacturing case and meso for the air transportation one). In Section 4 the main results of the performed work and the observations as per case are introduced. In Section 5 an integrated discussion of results as well as the elaborated framework is introduced. Finally but importantly, Section 6 summarizes the main conclusions, as well as the scientific and practical implications of the research, and its limitations.

\section{Literature Review}

While, as mentioned, sustainability is a trending topic, its definition has been the subject of multiple studies and debates since the 1980s [10] and it is still under a lot of debate due to its different dimensions [11]. Regarding organizational behavior, the accounting framework named Triple Bottom Line (TBL), considering three dimensions for reporting, the financial, the environmental and the social one, has been found useful to analyze sustainable value creation $[9,12]$. Some authors like [13] have explored the implications of IIoT for the TBL. While the adopted methodology was the semi-structured interviews, the main outcome was to emphasize the need for considering aspects like technical 
integration as well as data and information layers. Other authors emphasize the importance of the inter-relationships between the three dimensions to achieve real sustainable development [14].

Concerning business models, sustainability is still a hard topic because there is not a definitive design on how to operate an organization in a sustainable way. This happens because of the difficulties in keeping organizational design updated and because of the volatility of the value proposition, understood as customer willingness for their products [15]. While it was promised to extend the product life cycle by means of better services, the effective average of product life-cycle is continuously decreasing, in part because of the innovation schema fostering product replacement, and also because of the planned obsolescence, which reduces the product usability experience [16]. Volatility in products and services requires a higher degree of institutional knowledge to keep organization coping with the extreme dynamism, which requires continuous alignment between the organization itself and their stakeholders to provide added value to them.

The previous perspective for products raises interesting questions related to sustainability and other concepts like circular economy (CE), green economy (GE), and bioeconomy. While sustainability is understood as a wider referential framework, it is worth understanding CE and bioeconomy as resource-focused. Otherwise, GE has its focus on the processes, and it is more inclusive at the local level [17]. Therefore, because, in this research, the interest is more institutional, the adopted perspective on sustainability is process-oriented. In any case, it is important to remind that some studies present the $\mathrm{CE}$ as a condition for sustainability [18].

The interdependency between Industry 4.0 and sustainability theme has been confirmed in the last years by two systematic literature reviews on the field of Industry $4.0[19,20]$. In both of them, sustainability was identified as one of the main benefits of Industry 4.0, together with productivity optimization or automated knowledge and learning as examples. Seliger et al. ensure that shortly the increased value-added of Industry 4.0 will become more visible through more sustainable companies due to its enormous potential [21], making us conscious of the importance of taking this link into account. Specifically, in the manufacturing processes, Industry 4.0 was found to have the capacity to enhance operations for environmental sustainability [22].

The positive effects of knowledge sharing on the organization's sustainability has been identified, considering two dimensions: The intra-organizational and the inter-organizational following the available literature around the topic $[23,24]$. That link was also confirmed, through the capacity of companies with a proper knowledge management to face changes with higher success rates. On the intra-organizational knowledge side, there is growing attention to the processes to improve sustainability [25]. Furthermore, more specifically, the human resource division involvement has attracted research attention in the last years, with a focus on intra-organizational knowledge facilitation.

On the inter-organizational dimension of knowledge sharing, the link between the adaptability of inter-organizational information systems and the 17th Sustainable Development Goal (SDG) has been identified from the systems perspective, highlighting the importance of organizational learning mechanisms and knowledge sharing on that adaptation to keep the SDG on track.

There are also studies taking a different perspective to link sustainability and knowledge. That is the case of Tosic [26], in which research a significant correlation between investment in knowledge and human capital to increase the innovation and knowledge while remaining sustainable is found.

Within knowledge sharing, it is interesting to note that the intra-organizational dimension shows an influence on the performance of the inter-organizational one and based on that and the integrated framework, an approach for both aspects of knowledge sharing is suggested [27], including the individual and the organizational learning variables.

The importance of data and technologies to improve knowledge management within companies and between companies has been assessed through many articles linking them with performance [28], innovation and development [29], or engagement of the workforce [30]. The need for improved and increased knowledge sharing opportunities due to Industry 4.0 development is also a fact, but 
also, the other way around, Industry 4.0 can increase knowledge-sharing opportunities through the introduction of technologies that more efficiently support information sharing [31].

The improvement in knowledge sharing thanks to Industry 4.0 enabling technologies has been specifically identified in the manufacturing industry [32], as a factor that increases workers' engagement by giving them the chance to influence their workspace. That was tested through the application of technologies such as augmented reality or 3D simulation. In the air transport industry, the digitalization trend to improve knowledge sharing is an evolving subindustry [33]. On the technology side, the gamification concept was linked to Industry 4.0, that is revamping the knowledge sharing approach thanks to the introduced technical capabilities, and allowing companies to plan dynamic activities to improve employee engagement with knowledge sharing [34].

Traditionally the literature in the strategic management field suggests that firms must readapt competences and resources looking to maintain competitive advantages over time [22]. In this research, the organizational learning processes are hypothesized to be partially related to sustainable behavior.

It is also clear that there are new trends of digitalization, the circular economy and servitization are force firms to develop new types of competitive advantages, where not only the firm-level matters but also the network level through the exploitation of advantages of the ecosystem and enabling co-creation with partners [35].

An interesting research question in this research is related to discussing to what end digitalization in organizations has a positive impact on the business when increasing knowledge is a relevant factor. With that in mind, in this paper, we will review different strategies at meso levels, considering together the three industry trends: Industry 4.0, knowledge management and sustainability, because the dual links between digitalization, sustainability and knowledge sharing have been extensively treated in the literature as described above, but a lack of studies considering the three dimensions together was found, even though the indirect link has been mentioned in some case through the Innovation that supports the sustainability.

\section{Materials and Methods}

The paper looks to show how I4.0 can help to increase the organizational knowledge, in particular in rather complex environments. Indeed, the final interest is to understand to what end the increase of effectiveness implies also improvement in environmental performance, as one of the dimensions for sustainable development.

The selected approach is to discuss the effects of digitalization by focusing on its drivers, like the implementation of Industry 4.0, mainly oriented not only on production but also on the health of workers and environmental working conditions. This is relevant as several authors [36,37] have highlighted that technologies driving Industry 4.0 are in many cases developed in silos and manufacturers'initiatives are isolated and fragmented, therefore dangers will multiply and the net impact on OHS will be negative.

Actually, for increasing organizational knowledge it was decided to keep the focus on processes with high levels of worker participation at shopfloor, for two main reasons; the first one is that such processes relay mainly on implicit knowledge, and therefore, digitalization can help to formalize it. The second reason is that such cases have not so commonly been addressed through a quantitative research approach, offering a good opportunity to derive results beyond the direct and interested variables under analysis.

Methodologically, the case study method was chosen for two main reasons: (1) Because it offers the opportunity to investigate processes in-depth and has widely accepted suitability for gaining an understanding of a multidimensional phenomenon [38], and (2) because it opens a stream of multiple sources of evidence through, for example direct observations, but also document analysis, which improves the overall quality of the analysis, providing additional robustness [39].

However, in order to avoid trustworthiness concerns regarding dependability and integrity taken in an interpretive way [40], it was decided to cover also a case reflecting the interorganizational dimension. 
Therefore, a multiple-case design following theoretical replication logic was adopted [41], and it was decided to accomplish an analysis for the Industry 4.0 manufacturing applications at "micro" scale, having the opportunity to deeply understand the impacts of the hidden business effects and managerial decisions in terms of sustainability. Such an opportunity was created as the authors were running a research project looking to integrate workers in the Industry 4.0 context by increasing the explicit knowledge in non-regular processes happening in production.

To avoid bias, it was also decided to carry out an analysis from a "meso" scale for the air transport sector, where the impact of much more strategic and global initiatives also become relevant. By having such a triangulated view, between sectors and scales, the analysis can be enriched, and concerns about dependability and integrity avoided. For both cases, the focus will be to explore how digital transformation enables a higher level of transparency and better environmental performance related to different economic sectors at different scales of analysis. Indeed, it extends the concept defined in [42] for digitalization, as a process of converting analogue data into digital datasets and it enables the establishment of a framework for digitalization. Actually, both cases analyzed make it possible to create new and non-existing datasets where learning from them can strengthen the organizational knowledge.

After presenting the methodological dimension of the work, the main details for the setup of each of the cases are provided

\subsection{Manufacturing Case}

In order for an organization to step into the digital world, it is not just a matter of digitizing its working methods, products or services, but also strategies and business models need to be reviewed accordingly [43]. The Industry 4.0 paradigm, also including IIoT [44], IoT [37], RFID and several other drivers contributes to increasing their innovation and competitiveness.

While the technology evolves rather fast and it requires organizations to be adapted in a fast pace. There are a very large set of publications digging in different types of applications [45-48].

The attractiveness of this application case is to analyze the effects of digitalizations in organizations when addressing processes involving a high degree of variability. In most of the research, work demonstration case studies are focused on systematic processes with a high level of regularity [49-51]. In some of the cases, applications to integrate workers into the process have also been explored [52-54], which intrinsically means higher variability because of the human behavior.

The facility produces rebars for concrete construction both in civil works and buildings. The interesting type of products have very different geometric characteristics, as depicted in Figure 1 . The production scheduling comes from the classical ERP system, production at facility level is managed by the MES arma+ [55]. Then, production of specific items by cutting, blending and welding is fully managed by automatic machines connected to the MES system in such a way that the total number of items are tracked and counted machine by machine.

As the items are grouped depending on the quantities they are tracked by sticks attached to them and the inner logistics is based on a system of cranes.

The outdoor logistics relay on a truck from the industrial facility to the construction floor. However, preparations need to be carefully planned as the unload process usually needs to visit different construction sectors to deliver specific sets of rebars. Therefore, a specific disposal sequence of items as per layers in trucks needs to be carefully managed.

It is not surprising that the organizational knowledge of the company only relays on the MES information and what it uploads into the ERP. The planning of the loading process into trucks is the responsibility of the crane operators, who keep the details of the operational procedure, as it has no more manufacturing effects because it is the last step of production. Indeed, different crane operators have their own approach for the task, which introduces variability not only in terms of errors, but also in terms of performance, energy consumption, etc. Sadly, the organization does not have any information or knowledge about it, neither specific KPIs nor targets like reduction of product losses, reduction of re-submit logistics, etc. 


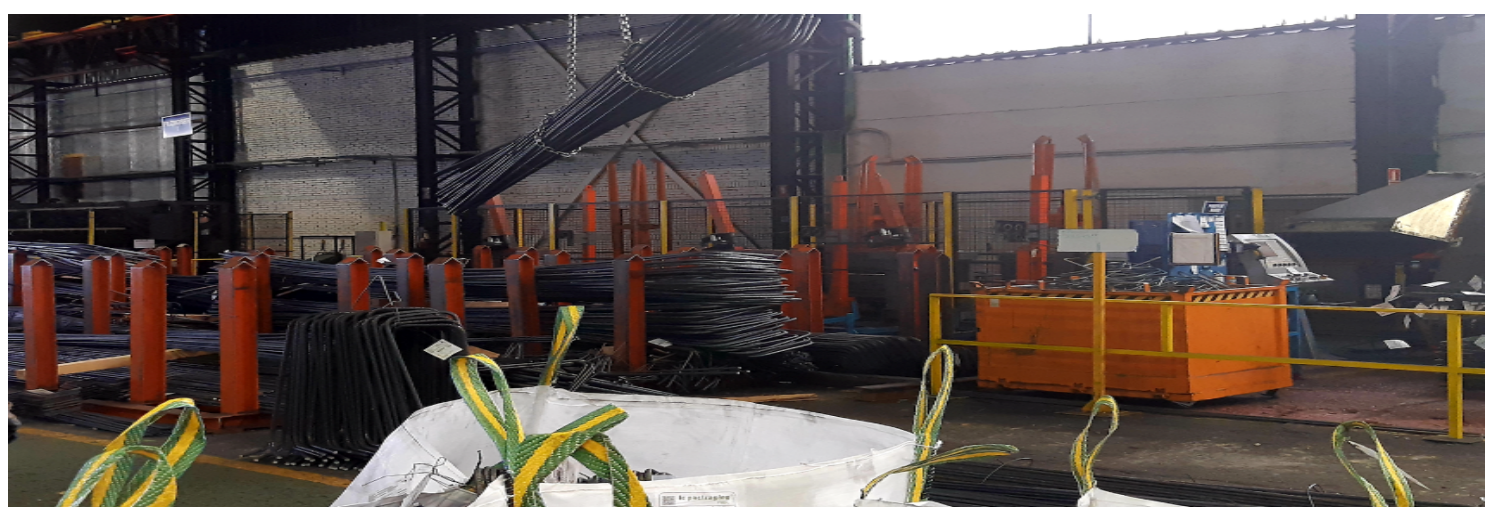

Figure 1. Perspective of different produced rebars.

While the configuration for products (see Figure 1) is so variable (specific delimited areas with columns, big fixed size boxes, white textile bags, etc.) it is almost impossible to standardize them. Therefore, the classical view of process normalization fails because there is not a finite and low number of configurations to describe. Even worse, the product load into the truck must consider the unload path into the construction yard, as different sets of rebars may need to be delivered into different sections of the construction yard because of several construction activities being carried out in parallel, which require to have different sets of rebars at different places at the same time.

In terms of institutional knowledge, this very last step in the rebars manufacturing significantly damages the whole setup, and the existing approach, which considers the two different kinds facilities, the first fully monitored in real time, based on the MES and bar-code guns, providing plenty of details about how performance, usage, demand for maintenance, and so on, and which evolves through time and as per order.The second one, focused on logistics for loading trucks and delivery, does not improve with significant variance in lasting operations and makes mistakes that damage the ensemble of the business. This also happens because of the segmentation between those two activities has not enough physical space to accommodate the produced items, and very frequently bottlenecks happen due to the lack of free space to place the set of items, which makes even harder the location work for crane operators, increasing the probability of some set of items getting lost for a specific truck (Figure 2).

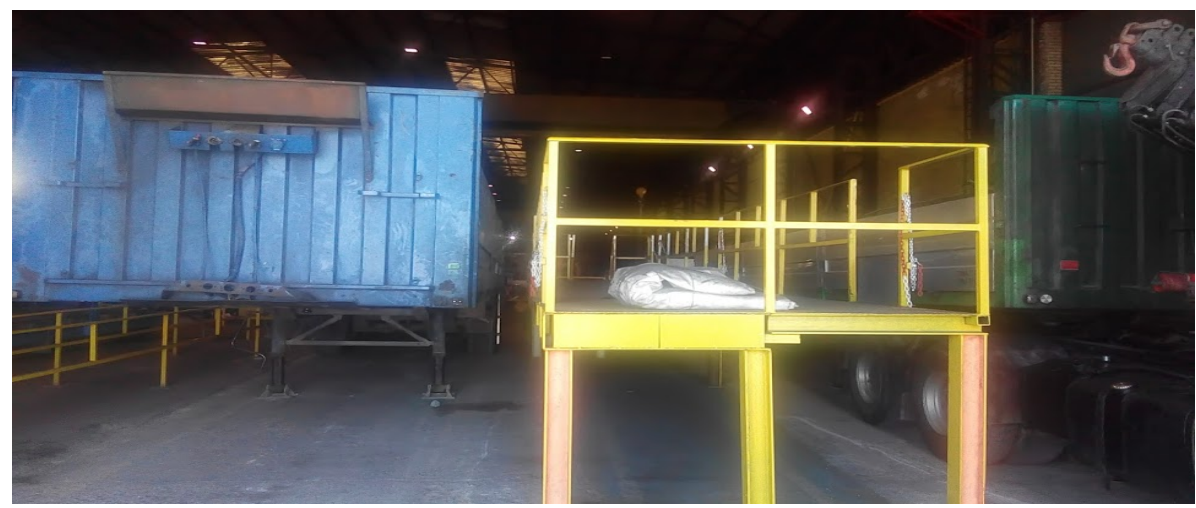

Figure 2. Perspective of two trucks loading platform. The crane operator moves up and down to effectively place the different items on-board.

To better show the difficulties experienced in locating items, Figure 3 shows the whiteboard crane operators regularly use to identify where the items related to a specific truck are located in the factory. It is seen how qualitative but still useful references are placed. Indeed, it is easy to understand potential mistakes in forgetting to note some particular items, incorrect erases, etc. 


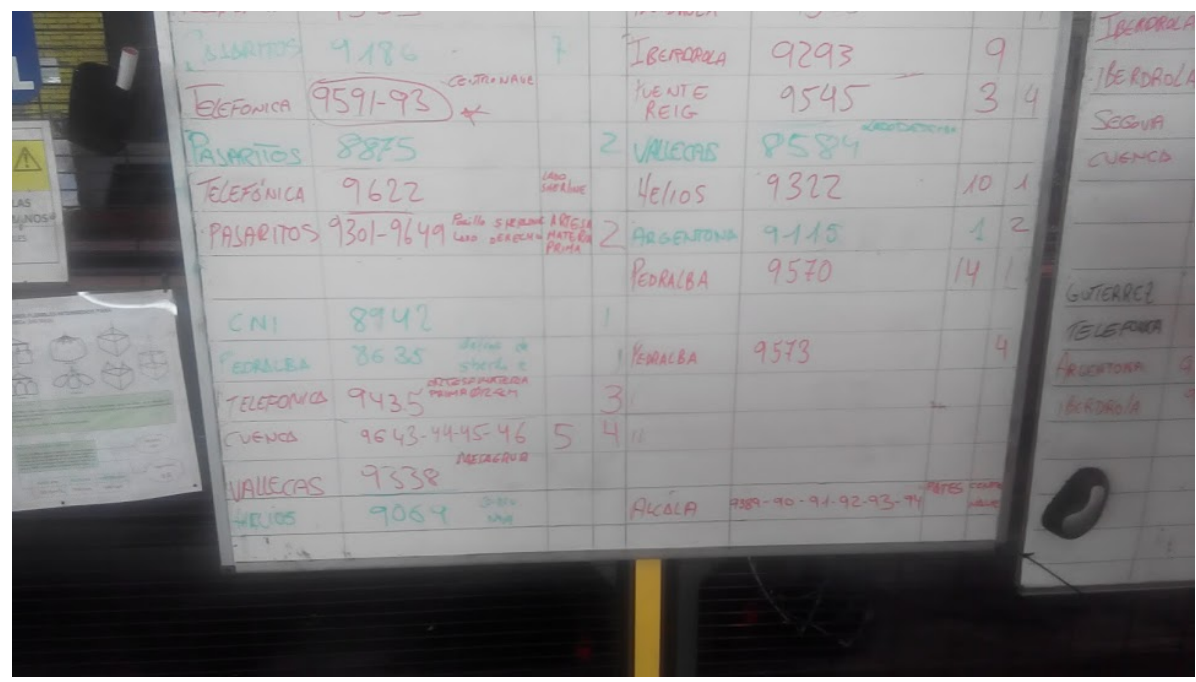

Figure 3. Whiteboard used to track item positions for different trucks.

\subsection{Air Transportation Case}

The air transport sector is the form of transport that has experienced the greatest improvement concerning efficiency since 1960 [56]. The global average occupancy in air transport is $81 \%$, above any other form of transport. Another fact is that around $80 \%$ of the aviation $\mathrm{CO}_{2}$ emissions come from long-haul flights $(>1500 \mathrm{~km})$ for which, depending on the goods transported or the passengers' needs, there is no other practical alternative. However, even with the efficiency rates reached, there is room for improvement, as recognized with the agreement of ICAO's 191 contracting states during the 39th congress in 2016. In that congress, CORSIA was agreed, implying "the adoption of a global market-based measure scheme to address $\mathrm{CO}_{2}$ emissions from international aviation" [57].

The International Air Transport Association (IATA) supports and pushes air transport sector sustainability through different digitalization initiatives. Three of them will be assessed in this research,

(a) FRED+ platform,

(b) Trajectory Sharing Platform (TSP) and

(c) e-Freight program.

A deep analysis of these programs is worthwhile in order to understand how they stimulate the cooperation between flight companies, stimulating their cooperation and bringing them measurement instruments.

\section{Results}

\subsection{Manufacturing Case}

The impact of limited institutional knowledge not only becomes a constraint to develop better organizational design [58], but it also has a direct effect both in economic performance and in environmental behavior. This is because making mistakes, like forgetting to load specific item-sets into a truck, means that a second delivery need to be performed which is less efficient, and indeed the amount of emissions associated with such working order is increased. Out of such extreme consequences some other effects can also be identified, like mistakes for failure to properly unload, which creates issues in construction yards. Indeed, because of intrinsic variability, different approaches to the loading process imply extra crane movements, more energy consumption and less performance.

Additional potential disturbing factors to be analyzed are the weather conditions; this is due to the particular market on construction increasing demand of rebars. However, high temperature stress [59] has significance for on the job satisfaction, performance and indirectly on environmental behavior. 
What is interesting is that failures in due time deliveries for specific items (due to misplacing them, forgetting them or any other reason) takes those item to scrap, although they have good quality records. Steel's recyclable properties are very high and the company has their own steel-making melting shops, therefore CE principles are applicable; in terms of accounting such products are considered as full loss of value, and specific KPIs are being placed to track them as this error means customer dissatisfaction and extra cost for extra delivery or urgent re-manufacturing in case of being unable to find items.

Therefore, this case analysis shows the relationship between organizational knowledge, job performance and both environmental factors and behavior at the organizational level.

To address the lack of organizational knowledge at the delivery function of the facility, but also the working conditions, the company decided to apply capabilities coming from Industry 4.0, in particular IIoT, IoT and Big Analytics, and two different shopfloors were investigated. A research project was set up to develop guidance on how to capture the good and bad practices, and better use such knowledge for improving the performance. The approach is designed to capture the sequence of production of items and crane movements to temporary store produced sets. Indeed, the crane operator is also tracked to learn what movements are done during truck loading. In addition heart rate, steps made and blood pressure of the crane operator is monitored every minute during the shift. Regarding worker parameters, a low cost smart-band (HBand (C) was selected and an android application was built to collect data from all the sensors every minute (see Figure 4).

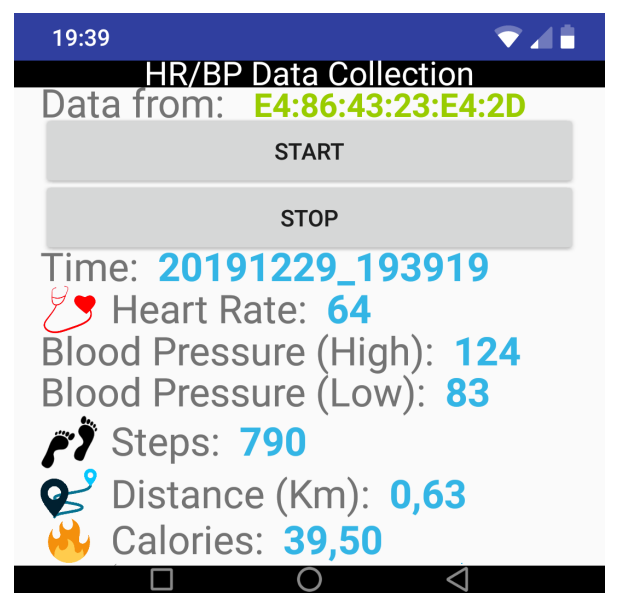

Figure 4. Main screen of the designed app for the worker's monitoring.

As a complementary source of information, there are local environmental parameters like temperature, relative humidity, $\mathrm{CO}_{2}$ levels and noise. To monitor the crane, crane hook and crane operator movements, the adopted technology was the Ultra Wide Band (UWB) [60]. The UWB uRTLS use several channels available on 3-7GHz) using the Decawave UWB chipset, in compliance with IEEE 802.15.4. The access to the data was implemented by using an API through a web service, using the json data structure. Different antennas were placed in some columns of the factory in such a way that triangulation with redundancy enables estimation of the position of tags with a precision below $35 \mathrm{~cm}$ (see Figure 5).

In addition to the previous data flows, environmental conditions were also collected indoors and outdoors, in order to have a broader context relevant to explaining the behavior.

The integration of data from different sources was carried out by using python programming language and a mongodb database. In particular, data coming from the worker smart-band is submitted directly by the android app. For this initial analysis, data collection of three weeks was performed, considering the three main crane operators and all the loaded trucks in this period. Preliminary analysis for worker trajectories and path duration, connected to crane load/unload cycles, has provide ANOVA tested evidence that behavior from different operators are significantly different, including 
the number of steps per operation. In addition, the indirect information of the number of item loaded enabled checking if someone was missed.

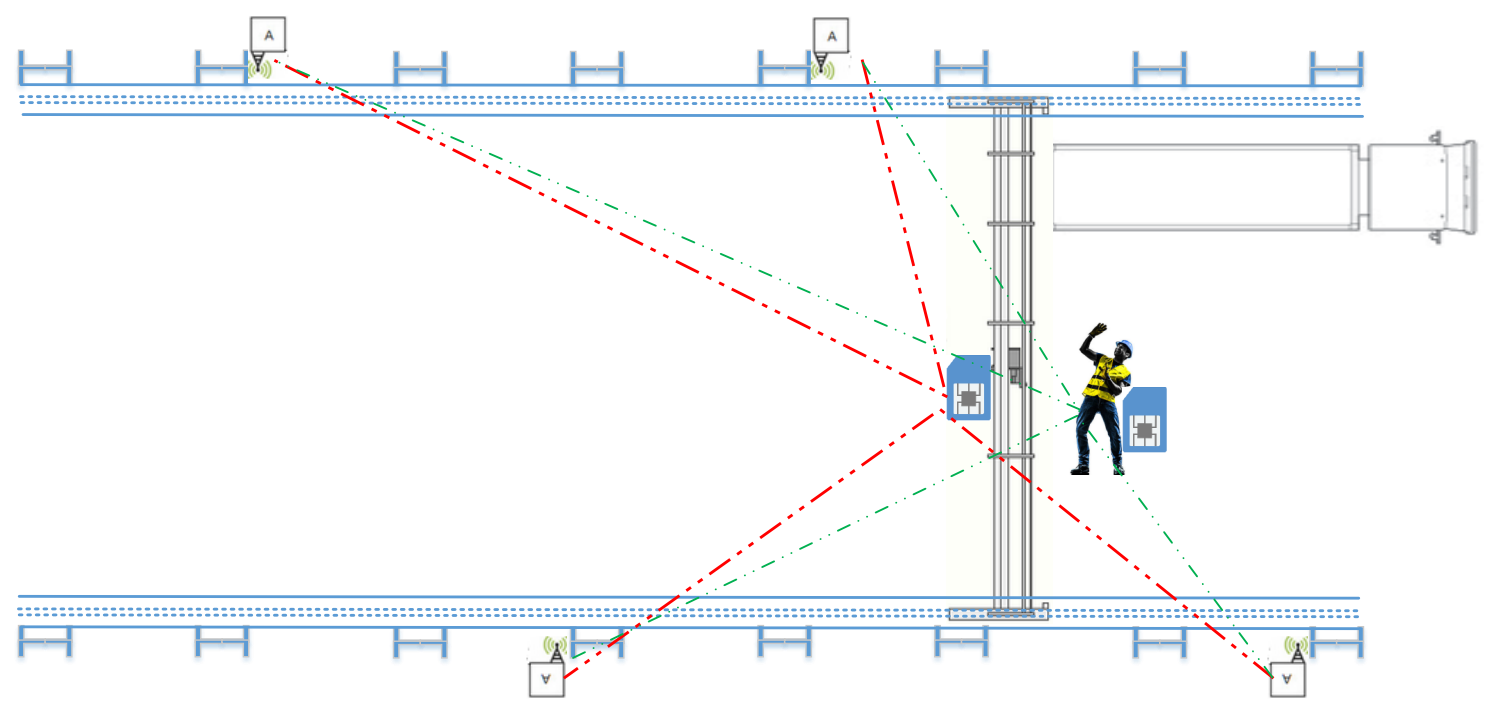

Figure 5. Layout of the Ultra Wide Band (UWB) devices as set up on the shopfloor.

\subsection{Air Transportation Case}

Since CORSIA's agreement, the digitalization of all the information required to monitor $\mathrm{CO}_{2}$ emissions has been highlighted as a challenge for the air transport industry. To tackle this challenge, IATA developed and launched the FRED+ platform. The main objective of FRED+ [61] is to facilitate, through an online system, the CORSIA reporting to all aircraft operators, verifiers and states subject to the ICAO agreement. As part of its functionalities, FRED+ allows airlines to connect with their respective administering authorities for data transmission, but also to contribute to the elaboration of an emission monitoring plan and to reporting on sustainable fuels. It also includes data validation with identification of data inaccuracies and outliers.

During the period in which CORSIA is active, the FRED+ platform is free of charges for CORSIA participants, making the digitalization of emissions data affordable not only for the big airlines and states, but medium and small ones.

Looking at additional benefits of FRED+ for airlines, the fact of sustainability reporting could represent a potential reduction in agency and legitimacy costs [62]. While the agreed reporting with CORSIA would help to reduce the $\mathrm{CO}_{2}$ emission of air transport, it is only the first step to monitoring and tracking the achievements of CORSIA's forecast objectives by 2035 [63]:

(a) Reduce $\mathrm{CO}_{2}$ by around 2.5 billion tonnes.

(b) Generate above 40 billion in climate finance.

To achieve the above objectives, the air transport sector has focused its attention on a four pillar action plan with three main objectives [64]. The most ambitious of those objectives is the reduction of $50 \%$ of net aviation $\mathrm{CO}_{2}$ emissions by 2050 in comparison to 2005 . The four pillars are related to improvements in the following areas:

(a) Technology, including the usage of alternative sustainable fuels. An example of the impact of this pillar on aviation is the evolution of aircraft fuel consumption. Since the beginning of jet travel, fuel efficiency improvement was between $15 \%$ and $20 \%$ compared with the previous aircraft generation. That is the main reason behind the reduction of $8 \%$ in US airline emissions between 2000 and 2014, while air traffic rose by 20\% [65]. Nowadays, aircraft manufacturers are working on several fronts to enhance aircraft sustainability, gathering technical feedback from aircrafts during their lifetime [66], or assessing the feasibility of other energy sources for aircraft 
like solar or hydrogen, and new wing designs [67]. What is clear is that the next sustainable developments for aircrafts will rely on breakthrough technologies because current ones have already reached their ceiling [68].

(b) Operations improvement. This pillar ranges from ground operations to flight trajectories. A very important point to take into account about this pillar is that operational improvements, in comparison with technology, could have an immediate impact on the entire air transport efficiency.

In the operational field, the study of the optimal trajectory has been broadly researched [69-71], in most of the cases linked to FCO. The FCO in the air transport sector is an old topic [72], and aside from the obvious business interests, sustainability is making it again a trending topic [73-76].

(c) Infrastructure. Concerning infrastructure, the air transport sector is already facing the digitalization challenges of the airports [77], and also the advantages of improving infrastructure efficiencies like ground operations [78] or even baggage handling [79].

Regarding sustainability improvement, the IPCC estimated that only in the USA the introduction of the recommended changes on air traffic management would represent savings of around 6.1 million pounds of fuel, equivalent to 12.7 million pounds of $\mathrm{CO}_{2}$ emissions [80].

All of the above only highlights the importance of this third pillar in improving the sustainability of air transport. Moreover, it is reinforced by the emergence of the models for assessing the sustainability of airports [81].

(d) Global market-based measure. This last pillar is required to accomplish the explained objectives. Even relying on the first three pillars, a potential gap could occur. To close that gap, international $\mathrm{CO}_{2}$ emissions trading must be considered as a temporary solution, as suggested by Absi et al. [82], while solutions coming from the other three pillars are implemented.

Through business intelligence and digitalization, aside from the FRED+ platform, IATA is proactively supporting the airline industry to improve the second and third pillars of the strategy, the efficiency of the operations and infrastructures, and therefore the sustainability, by reducing fuel consumption. In this direction, the Trajectory Sharing Platform (TSP) is the last initiative under analysis. The idea behind TSP comes from the "Flight and Flow Information for a Collaborative Environment" (FF-ICE, ICAO's project) [83], and it is specifically based on evidence of the importance of optimal trajectory management to improve operations' efficiency $[69,84,85]$.

The TSP aims to help the process of optimizing aircraft trajectories, based on the advanced measurement and trajectory management technologies of the new aircrafts (technology pillar). The TSP will facilitate the information sharing between cockpit crews and ATCs, supporting the vision of overall systematic operation, which results in improved use of available airspace and the fuel consumed by the aircrafts.

For a better understanding of the value-added by the TSP, it is important to understand the context. Every aircraft starts its trip with a flight path assigned by the correspondent ATC, considering various factors as other flights and congestion. The assigned path could vary based on different variables like the weather or the turbulences detected. Additionally, nowadays, the new aircrafts have thousands of sensors ( $>250] \mathrm{hl}, 000$ in the case of A350), which generate big amounts of information per time unit. That information is used by the flight profile optimizer of the aircraft to recommend the optimal flight path, which is shared with the flight crew through the electronic flight bag. The optimal flight path recommended by the FPO is usually not feasible to follow due to ATC restrictions or surrounding traffic. Not allowing the aircraft to adapt its trajectory to the optimal has a direct impact on fuel consumption [69], and it could imply extra fuel consumption of up to $30 \%$ on airport arrival procedures [88], or in the case of the continuous cruise phase of an Airbus A320 between 1\% and $2 \%$ of the trip fuel [89]. 
The third initiative, led by IATA, to increase air transport industry sustainability through digitalization, is the e-Freight program, which "aims to build an end-to-end paperless transportation process for air cargo" [90]. The most outstanding objective of the e-Freight program, concerning sustainability, is the elimination of more than 7800 tonnes of paper documents annually. This objective will be achieved through the digitalization of 20 documents related to air cargo that can be converted into 12 cargo XML standard messages. The e-Freight program was launched by IATA in 2006, with the involvement of stakeholders across the whole air cargo value chain, from carriers to customs authorities, and the ground handlers or the custom brokers, among others.

From a digitalization point of view, a relevant step of the e-Freight program was the introduction of the e-AWB in 2010 to convert the AWB document (see Figure 6) into an electronic document. We should notice that AWB is a critical document within air cargo contracting processes, and it constitutes the contract between a shipper and a carrier (airline). In terms of volume, in September 2018 were there 2.3 million AWBs, being 55.9\% e-AWBs.While real implementation underperformed slightly (by December 2017, the expected penetration was 62\%, but the real one was 52.6\%), still the progress is very significant [86]. One year later, the penetration of e-AWBs has increased significantly up to $66.6 \%[87]$.
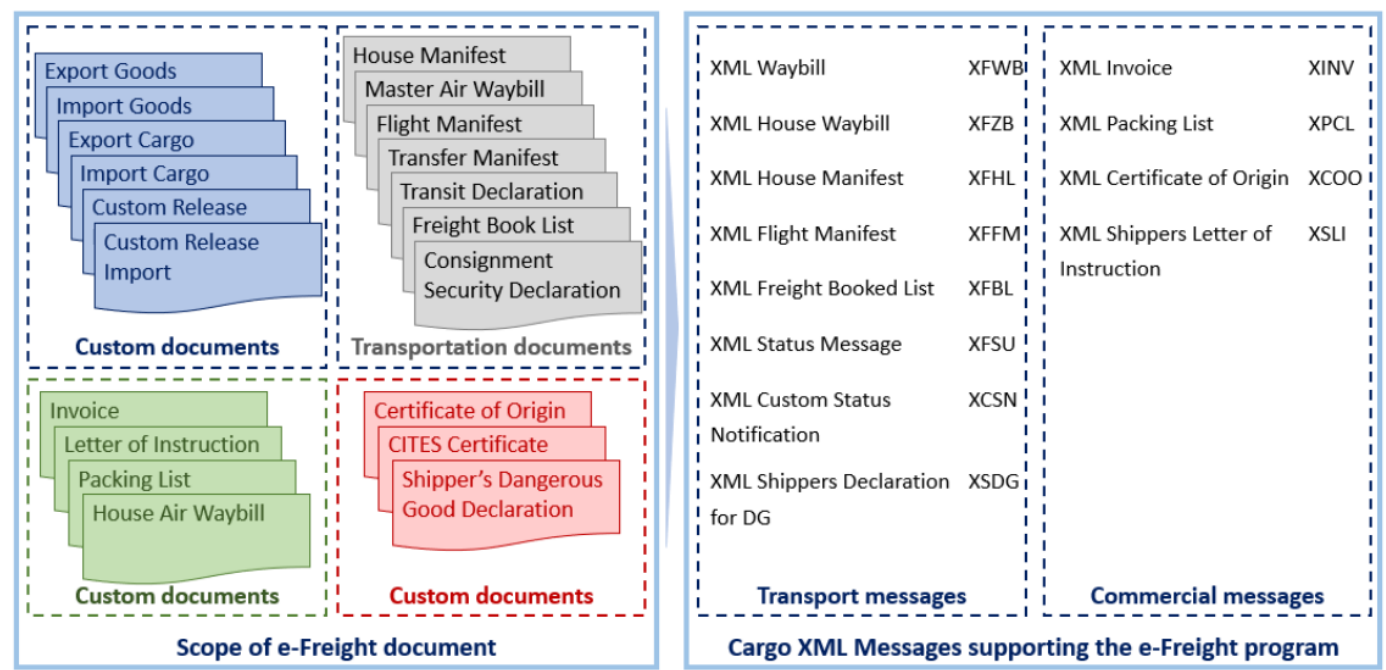

Figure 6. e-AWB files. (Source: The International Air Transport Association (IATA) https://bit.ly/ 2vBnLYy).

Aside from the mentioned digitalization related initiatives launched by IATA during the last years to improve air transport sector sustainability, there are other initiatives not directly related to the digitalization or IATA, that it is worthwhile to mention, at least the most relevant:

- The IEnvA (IATA Environmental Assessment) oriented to support airlines achieving ISO14001:2015 compliance.

- The "Single European Sky" program of the EU, aiming to improve ATM in Europe to make air traffic growth sustainable and environmentally friendly [91].

- Or the models developed by Eurocontrol to analyze the air quality around the airports (Open-ALAQS) or IMPACT for the combined analysis of noise, fuel consumption, and emissions [92] and not only in Europe.

\section{Discussion}

The current section has been structured following two cases considering their different levels: Micro for the manufacturing case and meso for the air transport case. Moreover, the three dimensions under study have been used to structure the discussion considering the findings. 
Based on the manufacturing case, it is possible to identify the benefits of increasing organizational knowledge on the shopfloor. This is the case of increasing the process knowledge about the location of item sets, which, from the initial trials, allowed to reduce by $3 \%$ the items to be sent and not finally loaded into the truck, which avoided unwanted additional delivery processes but, even better, reduced $12 \%$ the variability for truck loading duration. This result is aligned with the literature that inter-relate Industry 4.0 and sustainability improvement, which has shown a strong correlation between Industry 4.0 and the three dimensions of sustainability: Economic, environmental and social [93]. However, the figures obtained based only on the initial step of knowledge formalization are promising. Currently, more steps in knowledge creation are being accomplished, like to scan the barcode of the items being stocked, loaded into the trucks and unloaded. In this way, the aim is to reduce the process of locating the different items, which explains the variability in the duration of the load process. Therefore, as depicted in Figure 7, the bigger the focus in lean management, the larger the environmental improvement, even though the relationship is not direct. In fact, that relation is rejected by the same authors that support Industry 4.0 positive link with sustainability [93].

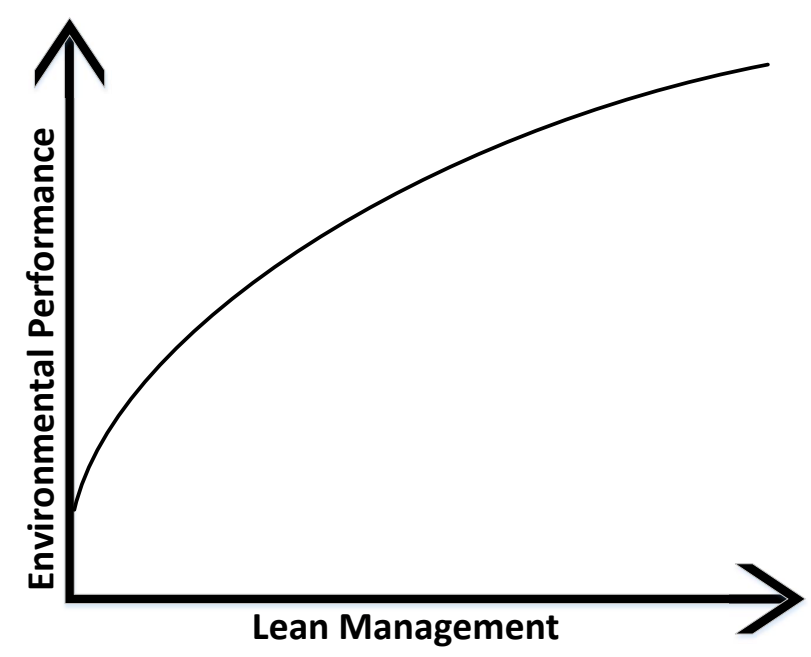

Figure 7. Relationship between organizational knowledge on the shopfloor and environmental performance.

The manufacturing case shows how intra-organizational knowledge sharing, supported by the digitalization of the work environment, could help to improve company operations' sustainability, in alignment with previously cited literature, which identified sustainability as one of the main benefits of industry digitalization $[19,20]$

In addition to the knowledge gained and the development carried out to estimate the stress of the operators based on the minute monitoring of heart rate and blood pressures, there was an interesting demand from $75 \%$ of the crane operators, who requested to have access to their data. No matter when the project dealing with the digitalization at the truck loading area was enforcing the GDPR requirements and no individual tracking was enabled, it was considered fair to attend to the demand of the workers, and to analyze the derived effects. The legal restrictions (GDPR) to share all the information reduce the value added to the sustainability of the operations thanks to factory digitalization and even though this intra-organizational knowledge hiding was due to external factor to the organization, it can be considered a negative consequence of intra-organizational knowledge hiding, with no influence from the knowledge management systems implemented in the company [94].

It is relevant to discuss how the management of the facility fostered the early adopters of technology by including relevant messages in training sessions, presenting the project as a good win-win opportunity for all the stakeholders, evidencing that such measurements will make it possible to justify heavy conditions with figures, which can help to find ways to implement protective actions, and delivering enough information through the union representation of workers. These actions, although managerial class, are considered essential in the effective usage, adoption and interest 
exhibited by participants, including the already indicated request to check their own data, which was not expected at the beginning of the project.

To address workers' demand, a regular job was implemented that every day delivers the specific records to a trello@ account to which every interested worker needs to subscribe. A statistical summary of the collected data for such workers per day is fed onto their dashboard, which also includes a link to a website with graphic details (see Figure 8). The interest of the workers to obtain more information about the data gathered denotes an interest to be engaged in the intra-organizational knowledge management to help with the their workspace potential redesign. On the process side, the case itself has the intention to improve sustainability through knowledge sharing [24].

\begin{tabular}{|c|c|c|c|c|c|c|}
\hline$\leftarrow \rightarrow C$ 畐 & 0 & O http: & $90 \%$ & ... $\nabla$ & Q Buscar & $\underline{\downarrow} \gg$ \\
\hline
\end{tabular}

\section{Report from 2019-12-22 11:00:00 until 2019-12-22 20:00:00}

\section{Device MAC: "E4:86:43:23:E4:2D"}

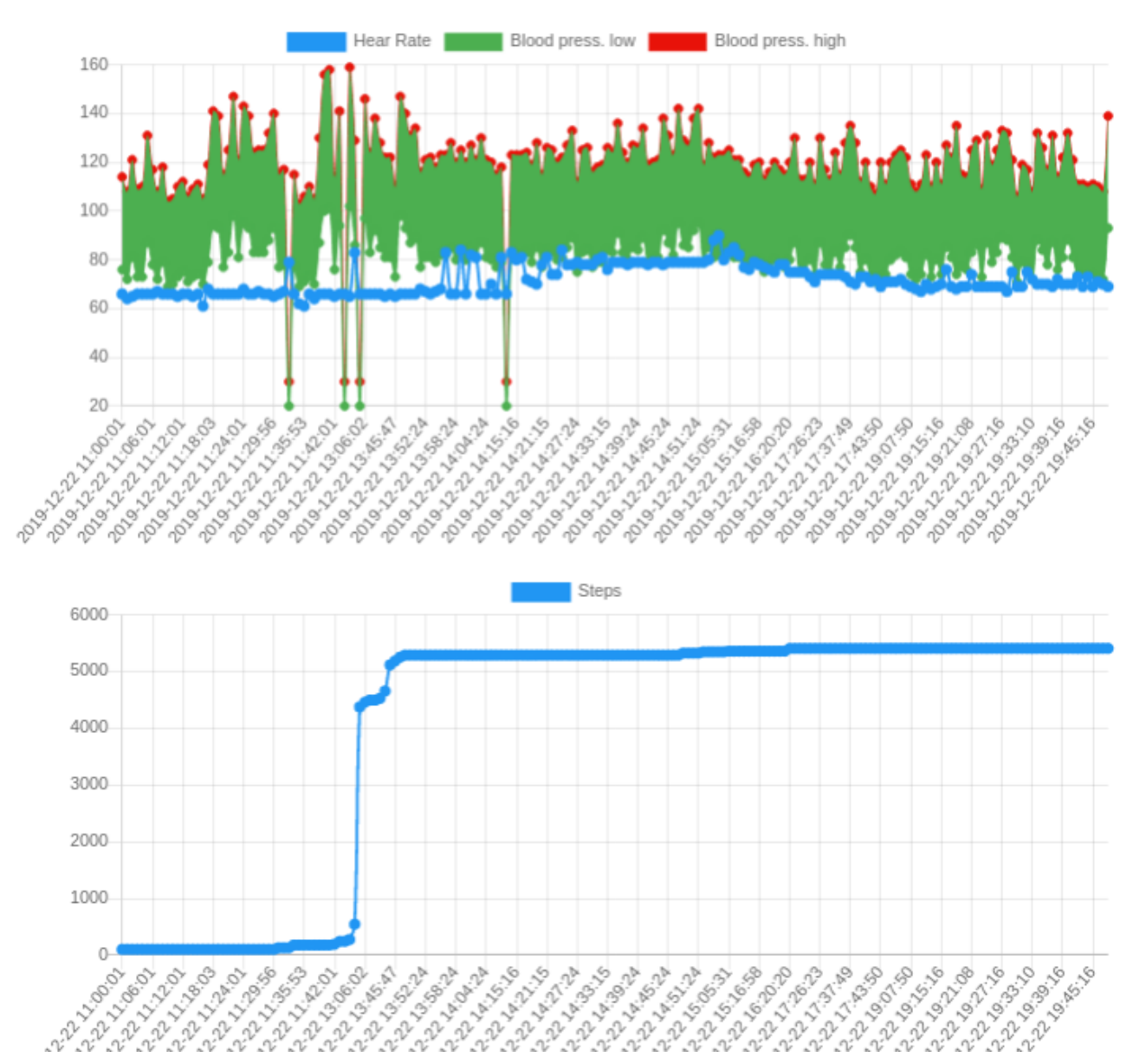

Figure 8. Webtool developed to inform workers about their parameters.

It is interesting to note the motivational effect that the availability of the dashboard brought to the workers. That effect is also supported by previous studies that link the implementation of social media platforms with the motivation of the employees to share knowledge internally [95]. It was also observed through this experience that when such information started to be consumed by workers, they became aware of the relationship between their parameters and the activities, and such 
personal implication is considered a positive factor to foster digitalization, as they start to request additional knowledge.

Some evidence observed from this research project is the added value of including highly variable human based tasks as candidates to contribute to increasing intra-organizational knowledge sharing [96]. Such an approach can make a difference in the particular case of CMfg configurations, where human activities can significantly impact the long-term stability and availability of such concepts.

For the ongoing manufacturing research project, the data collection is still being carried out for long-term learning, like the systematic association of human patterns like stress and environmental conditions. However, the initial short-term outcomes have provided a consistent view of potential contributions for integrating low cost but relevant data from IoT and IIoT into the business processes, bringing immediate effects over several indicators (see Figure 7).

The IATA case presented three initiatives in different stages; each of them with a different target, but all related to the usage of digitalization to improve sustainability. Due to the characteristics of IATA, as a trade association for the world's airlines, all the initiatives presented are oriented to improve inter-organizational knowledge sharing within the air transport sector. At the same time, the case of IATA is difficult to compare with the existing literature because the barriers faced for inter-organizational knowledge management are different to the ones experienced by profit-oriented organizations, which are subject to the paradox of sharing knowledge [97] for their benefit but hiding them at the same time to keep their strategic advantages.

There is a positive link between environmental sustainability performance and the increase of inter-organizational knowledge as a result of organizational learning [98], also in the case or air-transport, although it was only quantitively verified in the manufacturing case. In the IATA case, looking at Figure 9, the importance that inter-organizational knowledge sharing is going to have for sustainability, as recently confirmed through research [99], can be easily deducted. $\mathrm{CO}_{2}$ emission evolution depends on various innovation streams (intensive in knowledge), previously referred to as the four pillars: Technology, operations, infrastructure and global market-based measure. To facilitate that inter-organizational knowledge management that will enhance sector sustainability, proper knowledge governance will play a key role [100]. That management is facilitated by many air transport sector transversal stakeholders, like ICAO or IATA. In the manufacturing case, environmental benefits arise due to organizational learning from worker participation [101].

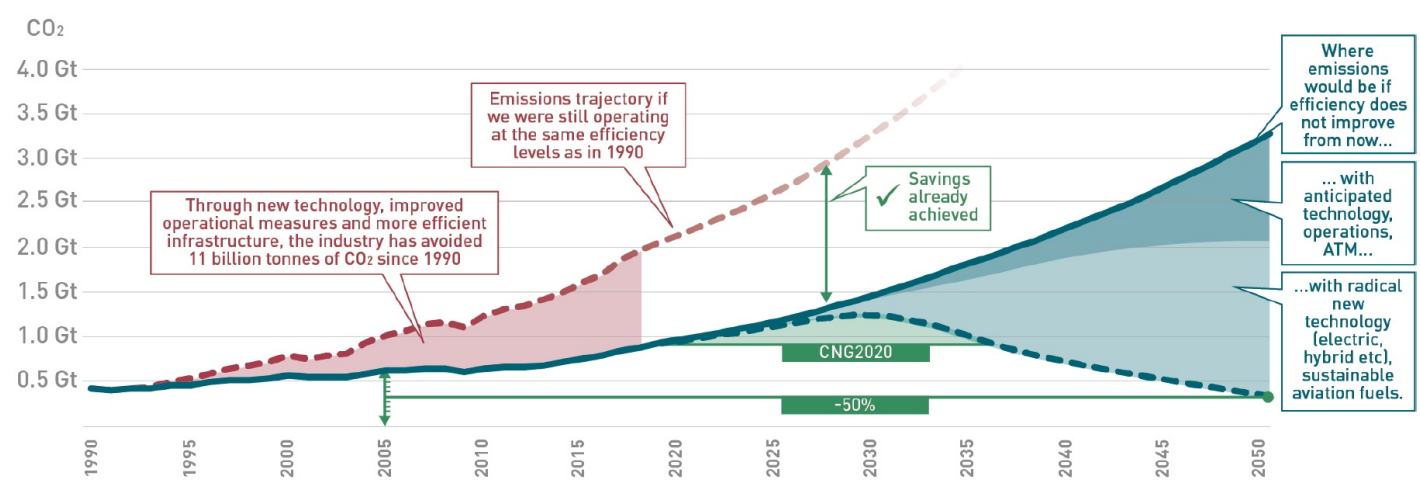

Figure 9. $\mathrm{CO}_{2}$ evolution and forecast. (Source: IATA https://bit.ly/2OSoKKO).

The role of IATA in all the initiatives presented develops and implements inter-organization systems adapted to the needs of the sector. The presented initiatives are adapted to the need for a more environmentally sustainable performance, but IATA has other initiatives linked to other industry needs, like the Billing Settlement Platform (BSP) "designed to facilitate and simplify the selling, reporting and remitting procedures of IATA Accredited Passenger Sales Agents, as well as improve financial control and cash flow for BSP Airlines" [102]. 
From this analysis, one of the outcomes is that different types of organizations can evidence the relationship between environmental behavior and knowledge sharing. Indeed, those drivers can be either internal knowledge acquisition as in the manufacturing case or external knowledge acquisition as in the IATA case, where the common measuring system, as well as the flight companies' cooperation through the platforms, build by IATA, enable such knowledge creation. From a more general perspective, it can be seen that drivers can be a combination of internal and external knowledge acquisition mechanisms, where the right figures will depend on the adopted strategy in the organization.

However, the intensity of the relationship depends on the relative location of each organization. This can be seen in Figure 10. When the organizational knowledge level is low, big outcomes regarding environmental performance are not expected, and actually if the performance is moderate, there are no additional incentives to improve, which means that its natural evolution is to reduce the future relative performance. If the performance is currently high, the future tendency in the short-term is to keep the position. When the organizational knowledge level is high, the incentive to increase the performance is higher than in the low-level case. In the case of moderate performance, the incentive to use opportunities is high and more opportunities are available. Such a combination enables a wider set of potential alternatives. In the case of current high performance, although the incentive is high as well, the set of options is limited, which means that future options are less than in the moderate case.

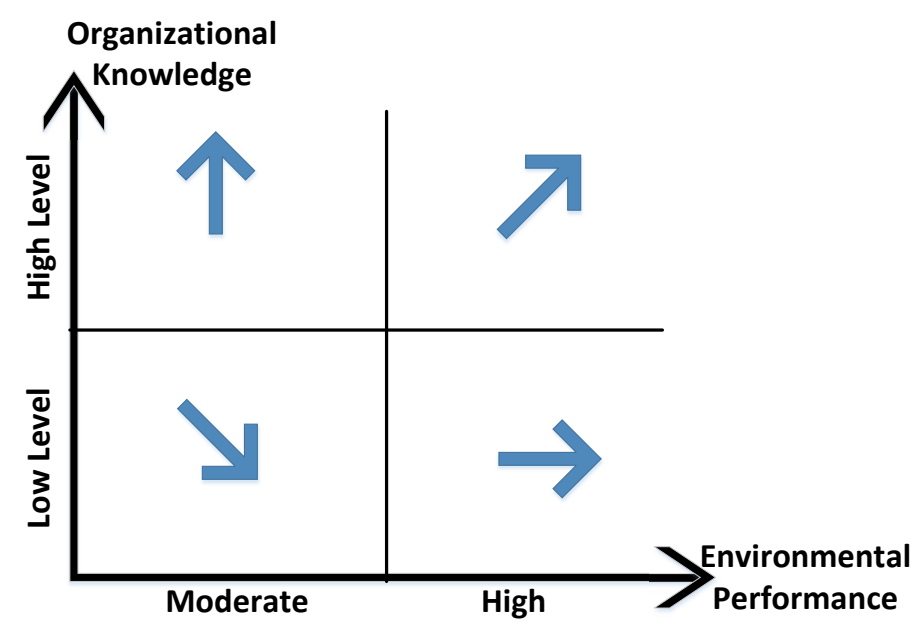

Figure 10. Interactive relationship between organizational knowledge and environmental performance.

\section{Conclusions}

In summary, we can conclude that during the last 15 years, the air transport industry has demonstrated a real commitment to environmental sustainability through tangible initiatives related to new aircraft technologies, enhanced operations or sustainable fuels. In this path, to improve air transport sector sustainability, the increased digitalization of airports and the adoption of Industry 4.0 provides significant relevance, as the IATA case studies showed. Nevertheless, aside from the industry sustainability improvements, the quantification of the impact that IATA initiatives have on air transport industry sustainability is a challenge that may be considered as a further research topic.

In a similar way, it was shown that in other industries like Industry 4.0 for construction, there are opportunities, even though the initiatives were not focused directly on sustainability, but in lean management or performance within a lean culture of variability reduction. It was evidenced that improvements impacting sustainability are also possible, but to be permanent they need to be adopted as explicit knowledge by the company. Therefore, no matter when technology is needed, strong management leadership is also required, and the bigger organizational knowledge capabilities, the bigger reward obtained. The integrated view derived from the research carried out is that knowledge increases when framed in a convincing strategy that can support direct and indirect improvements, 
including the sustainable dimension. This happens both inside the organizational context (intrinsic knowledge creation) but also in the case of multi-organizational contexts (extrinsic knowledge creation). The relevant aspect in all the cases is that the link between knowledge creation and sustainability performance when a specific strategy is implemented, and accountability through specific metric can be adopted and fostered by drivers like I4.0, Ilot, etc.

Additional lessons learnt are related to the significant added value of managing stakeholders' expectations, like enabling, promoting and reinforcing worker engagement with OHS and the explanations for findings. These dimensions can be also very significant when more innovative architectures like CMfg environments are considered, as nowadays the focus is just the track and control of production units through XPDL/BPEL kinds of languages. To consider workers' behavior inside the CMfg schema can bring additional perspective about process variability, which can contribute to further improvement of the whole system.

Regarding limitations of the research, although two different shopfloors have been investigated with different organizational knowledge levels, still the final figures involving long-term data capture, analysis, clustering and rule derivation and action implementation were not performed yet. Therefore, we can say that full quantification of the initiatives in both cases needs further research, and this will be accomplished in the near future. To this end, the effects that machine learning techniques can provide is also another dimension to be further investigated.

Author Contributions: T.P.R. was the main responsible for the air transportation case, J.O.-M. was the main responsible for the manufacturing case. All the authors have equally contributed to the methodology selection and deployment, Results and Discussions. Indeed, the writing was also a cooperative work. All authors have read and agreed to the published version of the manuscript.

Funding: This research was partially funded by the European Commission through the RFCS program, grant ID 793505. It got funding asl well from the Spanish Ministerio de Ciencia, Innovación y Universidades, through the grant RTI2018-094614-B.I00 (Smashing) of the Agencia Estatal de Investigación

Acknowledgments: The authors want to thank the EU RFCS research program for the support of this research through the grant with ID 793505 (WISEST project), and to thank the Spanish Ministerio de Ciencia, Innovación y Universidades, through the grant RTI2018-094614-B.I00 (Smashing project).

Conflicts of Interest: The authors declare no conflict of interest. The funders had no role in the design of the study; in the collection, analyses, or interpretation of data; in the writing of the manuscript, or in the decision to publish the results.

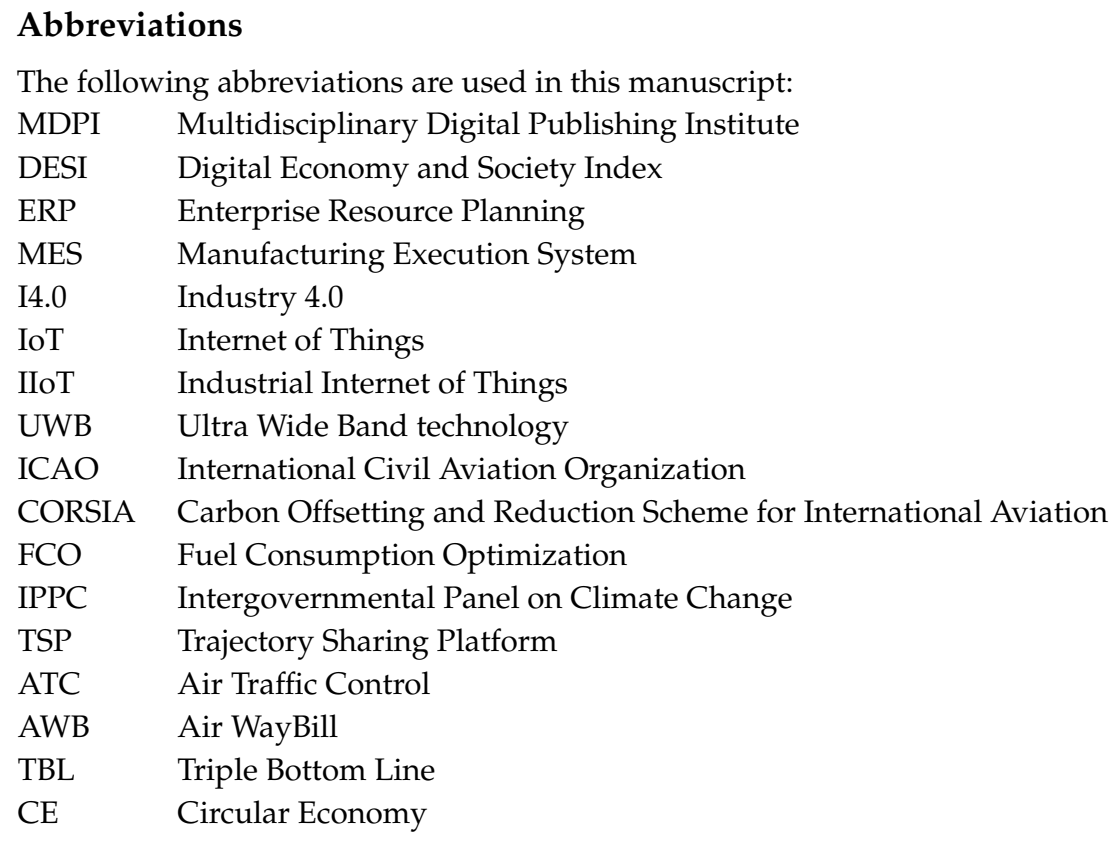




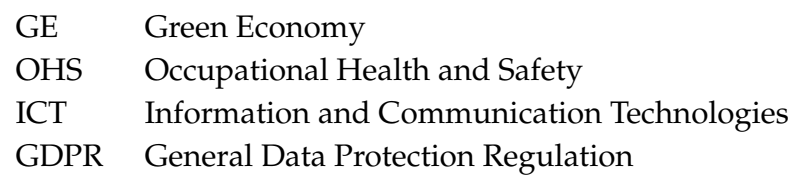

\section{References}

1. Bilge, P.; Seliger, G.; Badurdeen, F.; Jawahir, I. A novel framework for achieving sustainable value creation through industrial engineering principles. Procedia CIRP 2016, 40, 516-523. [CrossRef]

2. Mateus, A. DESI 2015 Digital Economy and Society Index Methodological note. EU Comm. Bruxelles. 2015, 1, 8-9.

3. Jovanović, M.; Dlačić, J.; Okanović, M. How Does the Digitalization Impact Society's Sustainable Development? Measures and Implications. Available online: https://www.researchgate.net/ profile/Milica_Jovanovic2/publication/325106114_How_does_the_digitalization_impact_society's_ sustainable_development_Measures_and_implications/links/5af6e648a6fdcc0c030d263e/How-does-thedigitalization-impact-societys-sustainable-development-Measures-and-implications.pdf (accessed on 30 November 2019).

4. Shrouf, F.; Gong, B.; Ordieres-Meré, J. Multi-level awareness of energy used in production processes. J. Clean. Product. 2017, 142, 2570-2585. [CrossRef]

5. Vogl, G.W.; Weiss, B.A.; Helu, M. A review of diagnostic and prognostic capabilities and best practices for manufacturing. J. Intell. Manuf. 2019, 30, 79-95. [CrossRef] [PubMed]

6. Pelletier, N.; Ustaoglu, E.; Benoit, C.; Norris, G.; Rosenbaum, E.; Vasta, A.; Sala, S. Social sustainability in trade and development policy. Int. J. Life Cycle Assess. 2018, 23, 629-639. [CrossRef]

7. Vié, A.; Colapinto, C.; La Torre, D.; Liuzzi, D. The long run sustainability of the European Union countries: Assessing the Europe 2020 strategy through a fuzzy goal programming model. Manag. Decis. 2019, 57, 523-542. [CrossRef]

8. Richter, C.; Kraus, S.; Brem, A.; Durst, S.; Giselbrecht, C. Digital entrepreneurship: Innovative business models for the sharing economy. Creat. Innov. Manag. 2017, 26, 300-310. [CrossRef]

9. Sullivan, K.; Thomas, S.; Rosano, M. Using industrial ecology and strategic management concepts to pursue the Sustainable Development Goals. J. Clean. Product. 2018, 174, 237-246. [CrossRef]

10. Brown, B.J.; Hanson, M.E.; Liverman, D.M.; Merideth, R.W. Global sustainability: Toward definition. Environ. Manag. 1987, 11, 713-719.10.1007/BF01867238. [CrossRef]

11. Peter Glavič, R.L. Review of sustainability terms and their definitions. J. Clean. Product. 2007, 15, 1875-1885. [CrossRef]

12. Colbert, B.A.; Kurucz, E.C. Three conceptions of triple bottom line business sustainability and the role for HRM. People Strategy 2007, 30, 21.

13. Alhaddi, H. Triple bottom line and sustainability: A literature review. Bus. Manag. Stud. 2015, 1, 6-10. [CrossRef]

14. Svensson, G.; Padin, C. Industry note: Sustainable development requires economic, social and environmental sustainability: A business perspective. Int. J. Agric. Innov. Technol. Glob. 2019, 1.

15. Kiel, D.; Müller, J.M.; Arnold, C.; Voigt, K.I. Sustainable industrial value creation: Benefits and challenges of industry 4.0. Int. J. Innov. Manag. 2017, 21, 1740015. [CrossRef]

16. Osterwalder, A.; Pigneur, Y.; Oliveira, M.A.Y.; Ferreira, J.J.P. Business Model Generation: A handbook for visionaries, game changers and challengers. Afr. J. Bus. Manag. 2011, 5, $22-30$.

17. Guiltinan, J. Creative destruction and destructive creations: environmental ethics and planned obsolescence. J. Bus. Eth. 2009, 89, 19-28. [CrossRef]

18. Geissdoerfer, M.; Savaget, P.; Bocken, N.M.; Hultink, E.J. The Circular Economy: A new sustainability paradigm? J. Clean. Product. 2017, 143, 757-768. [CrossRef]

19. Michela Piccarozzi, B.A.; Gatti, C. Industry 4.0 in Management Studies: A Systematic Literature Review. Sustainability 2018, 10, 3821. [CrossRef]

20. Kamble, S.S.; Gunasekaran, A.; Gawankar, S.A. Sustainable Industry 4.0 framework: A systematic literature review, identifying the current trends and future perspectives. Process Saf. Environ. Protect. 2018, 117, 408-425. [CrossRef] 
21. Stock, T.; Seliger, G. Opportunities of sustainable manufacturing in Industry4.0. Procedia CIRP 2016, 40, 536-541. [CrossRef]

22. De Sousa Jabbour, A.B.L.; Jabbour, C.J.C.; Foropon, C.; Filho, M.G. When titans meet: Can industry 4.0 revolutionise the environmentally-sustainable manufacturing wave? The role of critical success factors. Technol. Forecast. Soc. Chang. 2018, 132, 18-25. [CrossRef]

23. Tesavrita, C.; Suryadi, K.; Wiratmadja, I.I.; Govindaraju, R. Intra-Organizational and Inter-Organizational Knowledge Sharing in Collaborative Learning Process: A Conceptual Framework for SME. In Proceedings of the 2017 th International Conference on Industrial Engineering and Applications (ICIEA), Nagoya, Japan, 21-23 April 2017.

24. Wu, K.J.; Gao, S.; Xia, L.; Tseng, M.L.; Chiu, A.S.; Zhang, Z.. Enhancing corporate knowledge management and sustainable development: An inter-dependent hierarchical structure under linguistic preferences. Resour. Conserv. Recycl. 2019, 146, 560-579. [CrossRef]

25. Linneberg, M.S.; Madsen, M.T.; Nielsen, J.A. Micro-level translation of corporate sustainability: When strategy meets practice in the Danish hospitality sector. J. Clean. Product. 2017, 240, 118159. [CrossRef]

26. Tosic, B.; Zivkovic, N. Knowledge Management and Innovation in the Digital Era: Providing a Sustainable Solution. Adv. Econ. Bus. Manag. Res. 2019, 108.

27. Usman, M.; Ahmad, M.I.; Burgoyne, J. Individual and organizational learning from inter-firm knowledge sharing: A framework integrating inter-firm and intra-firm knowledge sharing and learning. Can. J. Adm. Sci. 2019, 36, 484-497. [CrossRef]

28. Sayyadi, M. How effective leadership of knowledge management impacts organizational performance. Can. J. Adm. Sci. 2019, 36, 30-38. [CrossRef]

29. Sukhorukov, A.; Koryagin, N.; Sulyagina, J.; Ulitskaya, N.; Eroshkin, S. Digital Transformation of Airline Management as the Basis of Innovative Development. Adv. Intell. Syst. Comput. 2020, 1115, 845-854.

30. Li, D.; Landström, A.; Fast-Berglund, Å.; Almström, P. Human-Centred Dissemination of Data, Information and Knowledge in Industry 4.0. Procedia CIRP 2019, 84, 380-386. [CrossRef]

31. Li, D.; Fast-Berglund, Å; Paulin, D. Current and future Industry 4.0 capabilities for information and knowledge sharing. Int. J. Adv. Manuf. Technol. 2019, 105, 3951-3963. [CrossRef]

32. Aromaa, S.; Liinasuo, M.; Kaasinen, E.; Bojko, M.; Schmalfuß, F.; Apostolakis, K.C.; Zarpalas, D.; Daras, P.; Özturk, C.; Boubekeuer, M. User Evaluation of Industry 4.0: Concepts for Worker Engagement. Adv. Intell. Syst. Comput. 2019, 876, 34-40.

33. Kikkawa, Y.; Mavin, T.J. Integrated Digitised Video Recordings in Postflight-Simulator Training: A Matter of Reflection. Prof. Pract.-Based Learn. 2018, 21, 103-121.

34. Kikkawa, Y.; Mavin, T.J. Gamification Concepts for Leveraging Knowledge Sharing in Industry 4.0. Int. J. Serious Games 2019, 6, 75-87.

35. Adams, G.L.; Lamont, B.T. Knowledge management systems and developing sustainable competitive advantage. J. Know. Manag. 2003, 7, 142-154. [CrossRef]

36. Badri, A.; Boudreau-Trudel, B.; Souissi, A.S. Occupational health and safety in the industry 4.0 era: A cause for major concern? Saf. Sci. 2018, 109, 403-411. [CrossRef]

37. Sun, S.; Zheng, X.; Villalba-Díez, J.; Ordieres-Meré, J. Indoor Air-Quality Data-Monitoring System: Long-Term Monitoring Benefits. Sensors 2019, 19, 4157. [CrossRef] [PubMed]

38. Eisenhardt, K.M. Agency theory: An assessment and review. Acad. Manag. Rev. 1989, 14, 57-74. [CrossRef]

39. Robert, Y. Case Study Research: Design and Methods; Sage Publications, Inc.: Thousand Oaks, CA, USA, 2003; Volume 761, p. 8.

40. Schwandt, T.A.; Lincoln, Y.S.; Guba, E.G. Judging interpretations: However, is it rigorous? Trustworthiness and authenticity in naturalistic evaluation. New Dir. Eval. 2007, 2007, 11-25. [CrossRef]

41. Marsden, T.; Murdoch, J. Introduction between the Local and the Global: Confronting Complexity in the Contemporary Food Sector. In Between the Local and the Global (Research in Rural Sociology and Development); Emerald Group Publishing Limited: Bingley, UK, 2006; pp. 1-8.

42. Rachinger, M.; Rauter, R.; Müller, C.; Vorraber, W.; Schirgi, E. Digitalization and its influence on business model innovation. J. Manuf. Technol. Manag. 2018, 30, 1143-1160. [CrossRef]

43. Zhao, H.; Zhao, Q.H.; Ślusarczyk, B. Sustainability and Digitalization of Corporate Management Based on Augmented/Virtual Reality Tools Usage: China and Other World IT Companies' Experience. Sustainability 2019, 11, 4717. [CrossRef] 
44. Kwon, S.; Jeong, J.; Shon, T. Toward Security Enhanced Provisioning in Industrial IoT Systems. Sensors 2018, 18, 4372. [CrossRef]

45. Fernández-Caramés, T.; Fraga-Lamas, P.; Suárez-Albela, M.; Díaz-Bouza, M. A fog computing based cyber-physical system for the automation of pipe-related tasks in the Industry 4.0 shipyard. Sensors 2018, 18, 1961. [CrossRef] [PubMed]

46. Hahn, G.J. Industry 4.0: A supply chain innovation perspective. Int. J. Product. Res. 2020, 58, $1425-1441$. [CrossRef]

47. Kabugo, J.C.; Jamsa-Jounela, S.L.; Schiemann, R.; Binder, C. Industry 4.0 based process data analytics platform: A waste-to-energy plant case study. Int. J. Electr. Power Energy Syst. 2020, 115. [CrossRef]

48. Zhang, Y.; Deng, R.H.; Zheng, D.; Li, J.; Wu, P.; Cao, J. Efficient and Robust Certificateless Signature for Data Crowdsensing in Cloud-Assisted Industrial IoT. IEEE Trans. Indu. Inf. 2019, 15, 5099-5108. [CrossRef]

49. Masood, T.; Egger, J. Augmented reality in support of Industry 4.0-Implementation challenges and success factors. Robot. Comput.-Integr. Manuf. 2019, 58, 181-195. [CrossRef]

50. Heberle, A.; Lowe, W.; Gustafsson, A.; Vorrei, O. Digitalization Canvas-Towards Identifying Digitalization Use Cases and Projects. J. Univers. Comput. Sci. 2017, 23, 1070-1097.

51. Simons, S. The AutFab smart factory-A learning factory for Industry 4.0. Atp Ed. 2018, 9, 46-61. [CrossRef]

52. Golan, M.; Cohen, Y.; Singer, G. A framework for operator-Workstation interaction in Industry 4.0. Int. J. Product. Res. 2019. [CrossRef]

53. Safeea, M.; Neto, P.; Bearee, R. On-line collision avoidance for collaborative robot manipulators by adjusting off-line generated paths: An industrial use case. Robot. Auton. Syst. 2019, 119, 278-288. [CrossRef]

54. Jesus Roldan, J.; Crespo, E.; Martin-Barrio, A.; Pena-Tapia, E.; Barrientos, A. A training system for Industry 4.0 operators in complex assemblies based on virtual reality and process mining. Robot. Comput.-Integr. Manuf. 2019, 59, 305-316. [CrossRef]

55. Graitec, G. Solutions for the Construction; Steel \& Concrete Industry. Available online: https://www.armaplus. $\mathrm{com} /$ (accessed on 20 October 2019).

56. ATAG. Fact \& Figures. Available online: http://www.atag.org/facts-figures.html (accessed on 18 Octomber 2019).

57. IATA. Carbon Offsetting for International Aviation. Available online: https://www.iata.org/policy/ environment/Documents / paper-offsetting-for-aviation.pdf (accessed on 18 Octomber 2019).

58. Hillman, D.R.; Werner, T.K. Capturing Generation-Based Institutional Knowledge Utilizing Design Thinking. Perform. Improv. 2017, 56, 28-36. [CrossRef]

59. Dehghan, H.; Mobinyzadeh, V.; Habibi, P. The Effects of Heat Stress on Job Satisfaction, Job Performance and Occupational Stress in Casting Workers. Jundishapur J. Health Sci. 2016, 8, 1-6. [CrossRef]

60. Macoir, N.; Bauwens, J.; Jooris, B.; Van Herbruggen, B.; Rossey, J.; Hoebeke, J.; De Poorter, E. Uwb localization with battery-powered wireless backbone for drone-based inventory management. Sensors 2019, $19,467$. [CrossRef] [PubMed]

61. IATA. IATA FRED+ General Presentation. Available online: https://www.iata.org/whatwedo/ environment/Documents/fred+_general_presentation.pdf (accessed on 30 November 2019).

62. Migdadi, Y.K.A.A. Identifying the best practices of airlines' green operations strategy: A cross-regional worldwide survey. Environ. Q. Manag. 2018, 28, 21-32. [CrossRef]

63. IATA. Carbon Offsetting Scheme for International Aviation (CORSIA). Available online: https://www.iata. org/policy/environment/Pages/corsia.aspx (accessed on 15 November 2019).

64. IATA. Climate Change. Available online: https://www.iata.org/policy/environment/Pages/climatechange.aspx (accessed on 1 December 2019).

65. ATAG. Aviation Climate Solutions. Available online: https://aviationbenefits.org/media/125796/AviationClimate-Solutions_WEB.pdf (accessed on 30 November 2019).

66. Husain, W.W.; Shah, S.A. Potential Aircraft Design Improvement and Sustainability Through Feedback Information. Int. J. Eng. Technol. 2018, 7, 221-224.

67. Ahmed, T.; Kurtulus, D.F. Technology Review of Sustainable Aircraft Design. In Sustainable Aviation; Springer: Cham, Switzerland, 2019; pp. 137-152.

68. Iemma, U.; Pisi, Vitagliano, F.; Centracchio, F. Multi-objective design optimization of sustainable commercial a-ircraft: Performance and costs. Int. J. Sustain. Eng. 2016, 10, 147-157. [CrossRef]

69. García-Heras, J.; Soler, M.; Sáez, F.J. A comparison of optimal control methods for minimum fuel cruise at constant altitude and course with fixed arrival time. Procedia Eng. 2014, 80, 231-244. [CrossRef] 
70. Lee, K.C.; Tsai, W.H.; Yang, C.H.; Lin, Y.Z. An MCDM approach for selecting green aviation fleet program management strategies under multi-resource limitations. J. Air Transp. Manag. 2018, 68, 76-85. [CrossRef]

71. Cavcar, A.; Cavcar, M. Impact of aircraft performance differences on fuel consumption of aircraft in air traffic management environment. Aircr. Eng. Aerosp. Technol. 2004, 6, 502-515. [CrossRef]

72. Singh, V.; Sharma, S.K. Fuel consumption optimization in air transport: A review, classification, critique, simple meta-analysis, and future research implications. Eur. Transp. Res. Rev. 2015, 7, 12. [CrossRef]

73. Hammad, A.W.; Rey, D.; Bu-Qammaz, A.; Grzybowska, H.; Akbarnezhad, A. Mathematical optimization in enhancing the sustainability of aircraft trajectory: A review. Int. J. Sustain. Transp. 2019. [CrossRef]

74. Matthes, S.; Team, A. Multi-criteria Environmental Impact Assessment and Optimisation of Aircraft Trajectories. 7th SESAR Innov. Days 2017, 4, 1-42.

75. Matthes, S.; Grewe, V.; Dahlmann, K.; Frömming, C.; Irvine, E.; Lim, L.; Linke, F.; Lührs, B.; Owen, B.; Shine, K. A Concept for Multi-Criteria Environmental Assessment of Aircraft Trajectories. Aerospace 2017, 4, 42. [CrossRef]

76. Lim, Y.; Gardi, A.; Sabatini, R. Optimal aircraft trajectories to minimize the radiactive impact of contrails and CO2. Energy Procedia 2017, 110, 446-452. [CrossRef]

77. Zaharia, S.E.; Pietreanu, C.V. Challenges in airport digital transformation. Transp. Res. Procedia 2018, 35, 90-99. [CrossRef]

78. Kovynyov, I.; Mikut, R. Digital technologies in airport ground operations. Netnomics 2019, $20,1-30$. [CrossRef]

79. Koenig, F.; Found, P.A.; Kumar, M. Condition monitoring for airport baggage handling in the era of industry 4.0. J. Q. Maint. Eng. 2019, 25, 435-451. [CrossRef]

80. IPCC. Aviation and the Global Atmosphere. Available online: https://archive.ipcc.ch/ipccreports/sres / aviation/index.php?idp=0 (accessed on 1 December 2019).

81. Kumar, A.; Aswin, A.; Gupta, H. Evaluating green performance of the airports using hybrid BWM and VIKOR methodology. Tourism Manag. 2020, 76, 103941. [CrossRef]

82. Absi, N.; Dauzère-Pérès, S.; Kedad-Sidhoum, S.; Penz, B.; Rapine, C. Lot sizing with carbon emission constraints. Eur. J. Op. Res. 2013, 227, 55-61. [CrossRef]

83. ICAO. Flight \& Flow Information for a Collaborative Environment. Available online: https://www.icao.int/ airnavigation/FFICE/Pages/default.aspx (accessed on 12 January 2019).

84. Stephen, A.; Daniel Ferro, A.N.; Chapelle, J.P. Large scale validations of enhanced Conflict Management functions. The key contribution of accurate ADS-C ATN B2 trajectory data. In Air Traffic Management Requirements and Performance Panel (Atmrpp). Thirty-Seventh Working Group Meeting; ICAO (International Civil Aviation Organization): Montreal, QC, Canada, 2019.

85. Suhang, C. The First Initial Four-dimensional Trajectory (I4D) Flight Trial in China. In Air Traffic Management Requirements and Performance Panel (Atmrpp). Thirty Seventh Working Group Meeting; ICAO (International Civil Aviation Organization): Montreal, QC, Canada, 2019.

86. Sauv, M. eAWB Implementation Playbook. Available online: https://www.iata.org/contentassets/ 6c6b8373246b4b2db532ff9c89bee5a7 / e-awb-implementation-playbook.pdf (accessed on 18 October 2019).

87. Sauv, M. eAWB Implementation Playbook. Available online: https://www.iata.org/contentassets/ 6c6b8373246b4b2db532ff9c89bee5a7 / e-awb-monthly-report-r17.pdf (accessed on 10 January 2020).

88. Ramon, A.; Jean Mere, D.D.; Miquel, T. Flight Management System Pathfinding Algorithm for Automatic Vertical Trajectory Generation. In Proceedings of the 2018 IEEE/AIAA 37th Digital Avionics Systems Conference (DASC), London, UK, 23-27 September 2018; doi:10.1109/DASC.2018.8569254. [CrossRef]

89. Dalmau, R.; Prats, X. How much fuel and time can be saved in a perfect flight trajectory? In Proceedings of the 6th International Congress on Research in Air Transportation (ICRAT), Istanbul, Turkey, 26-30 May 2014.

90. IATA. e-Freight. Available online: https://www.iata.org/whatwedo/cargo/e/efreight/Pages/index.aspx (accessed on 18 October 2019).

91. EU. Single European Sky. Available online: https://ec.europa.eu/transport/modes/air/ses_en (accessed on 18 October 2019).

92. Eurocontrol. Environment. Available online: https://www.eurocontrol.int/environment (accessed on 18 October 2019).

93. Varela, L.; Araújo, A.; Ávila, P.; Castro, H; Putnik, G. Evaluation of the Relation between Lean Manufacturing, Industry 4.0, and Sustainability. Sustainability 2019, 11, 1439. [CrossRef] 
94. Serenko, A.; Bontis, N. Understanding counterproductive knowledge behavior: Antecedents and consequences of intra-organizational knowledge hiding. J. Know. Manag. 2016, 20, 1199-1224. [CrossRef]

95. Vuori, V.; Okkonen, J. Knowledge sharing motivational factors of using an intra-organizational social media platform. J. Know. Manag. 2012, 16, 592-603. [CrossRef]

96. Indre Maurer, V.B.; Ebers, M. The Value of Intra-organizational Social Capital: How it Fosters Knowledge Transfer, Innovation Performance, and Growth. Organ. Stud. 2011, 32, 157-185. [CrossRef]

97. Loebbecke, C.; van Fenema, P.C.; Powell, P. Managing inter-organizational knowledge sharing. J. Strateg. Inf. Syst. 2015, 25, 4-14. [CrossRef]

98. Birou, L.M.; Green, K.W.; Inman, R.A. Sustainability knowledge and training: Outcomes and firm performance. J. Manuf. Technol. Manag. 2019, 30, 294-311. [CrossRef]

99. Payán-Sánchez, B.; Plaza-Úbeda, J.A.; Pérez-Valls, M.; Carmona-Moreno, E. Social Embeddedness for Sustainability in the Aviation Sector. Corp. Soc. Resp. Environ. Manag. 2018, 25, 537-553. [CrossRef]

100. Fang, S.Y.C.; Hsu, W. Inter-organizational knowledge transfer: The perspective of knowledge governance. J. Know. Manag. 2013, 17, 943-957. [CrossRef]

101. Rothenberg, S. Knowledge content and worker participation in environmental management at NUMMI. J. Manag. Stud. 2003, 40, 1783-1802. [CrossRef]

102. IATA. BSP Definition. Available online: https://www.iata.org/en/services/finance/bsp (accessed on 21 November 2020).

(C) 2020 by the authors. Licensee MDPI, Basel, Switzerland. This article is an open access article distributed under the terms and conditions of the Creative Commons Attribution (CC BY) license (http:// creativecommons.org/licenses/by/4.0/). 